\title{
Neuromyelitis optica: a challenging diagnosis at secondary hospital
}

\author{
Anna Paula Romero de Oliveiraa, Patrícia Tarantoc, Livia Herbst ${ }^{c}$, Andre Kiriharac,

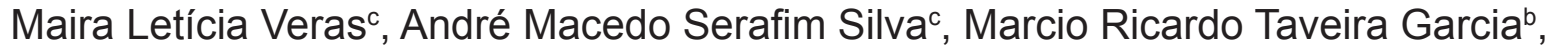 \\ Angelina Maria Martins Lino ${ }^{c, d}$
}

Oliveira APR, Taranto P, Herbst L et al. Neuromyelitis optica: a challenging diagnosis at secondary hospital. Autopsy Case Rep [Internet]. 2013;3(1): 53-61. http://dx.doi.org/10.4322/acr.2013.008

\section{ABSTRACT}

Known since the 19th century, neuromyelitis optica (NMO), or Devic's disease, is an idiopathic immune-mediated inflammatory demyelinating disease of the central nervous system selectively affecting the optic nerve and spinal cord. Commonly diagnosed in demyelinating diseases reference centers, we report an 18-year-old female patient who sought medical attention with a 3-month history of weight loss, headache, and vomiting, followed by diplopia, a burning sensation over the lower limbs, and difficulty walking. A few days prior to hospital admission, the muscle strength in her lower limbs became worse and ascended to the upper limbs associated with sensory changes in the trunk and voiding dysfunction. At admission, the neurological examination was consistent with a spinal cord syndrome. After few days of hospitalization, she was tetraplegic with severe signs of brainstem involvement requiring mechanical ventilatory support. Intravenous methylprednisolone and cyclophosphamide were promptly started after ruling out the diagnosis of infectious disease and cord compression. Due to no substantial early improvement, intravenous immunoglobulin was also used. From then on, the neurological status gradually improved. Magnetic resonance imaging showed extensive demyelinating features in the spinal cord, and the serum $\lg G$ autoantibody was negative. The patient was referred to a tertiary neurological reference center where she remains under treatment.

Keywords: Neuromyelitis Optica; Demyelinating Diseases; Respiratory Insufficiency; Magnetic Resonance Imaging; Pulse Therapy; Drug.

\section{CASE REPORT}

A previously healthy, 18-year-old female patient of African descent sought medical care with a history of weight loss of $14 \mathrm{~kg}$ during the last 3 months simultaneously with headache and vomiting. Two weeks after the onset of the symptoms, she started with diplopia and a burning sensation over the lower limbs that lasted for a month and progressed to face and scalp allodynia. She also had gait instability. A few days before hospital admission, the muscle strength of her lower limbs

\footnotetext{
a Scientific Division - Instituto de Infectologia Emílio Ribas, São Paulo/SP - Brazil.

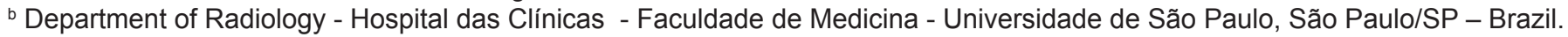

${ }^{c}$ Department of Internal Medicine - Hospital Universitário - Universidade de São Paulo, São Paulo/SP - Brazil.

d Department of Neurology - Hospital das Clínicas - Faculdade de Medicina - Universidade de São Paulo, São Paulo/SP - Brazil.
}

Copyright $\odot 2013$ Autopsy and Case Reports - This is an Open Access article distributed of terms of the Creative Commons Attribution NonCommercial License (http://creativecommons.org/licenses/by/3.0/) which permits unrestricted non-commercial use, distribution, and reproduction in any médium provided article is properly cited. 
became impaired and ascended to the upper limbs. This was associated with sensory changes in the trunk and urinary incontinence.

Initial examination showed an ill-looking patient with preserved cognitive functions, emaciated, pale, acyanotic, and with stable hemodynamic parameters. She denied dyspnea. Neurological examination showed slight asymmetric tetra paresis with muscular strength of grade 0 in the lower right limb and grade 3 in the upper right limb, and grade 1 in the lower left limb and grade 3 in the upper left limb. Deep tendon reflexes were absent in the upper limbs but were brisk with extensor plantar response in the lower limbs. All sensory modalities were compromised in limbs and trunk at T2 level. Cranial nerves were normal. Catheterization was necessary due to voiding dysfunction.

Initial laboratory workup included ANA and other inflammatory markers; serology for hepatitis $B$ and $C, H I V, H T L V$, and syphilis showed negative results; blood and urine cultures were also negative. The lumbar cerebral spinal fluid (CSF) analysis disclosed slight inflammatory changes (Table 1) with negative results for China ink and cultures (aerobic, fungal, and acid fast bacilli). The brain and spine computed tomographies were normal.

After 3 days in hospital, she rapidly evolved with plegia in all limbs, nasal voice and swallowing disturbances with preserved bulbar reflexes, vertical nystagmus, bilateral internuclear ophthalmoparesis, and acute respiratory failure that required mechanical ventilatory support. Magnetic

Table 1 - Lumbar cerebrospinal fluid analysis

\begin{tabular}{ccc}
\hline Parameter & Result & Reference value \\
\hline White blood count cell/mm ${ }^{3}$ & 11 & $1-4$ \\
Lymphocytes \% & 93 & $50-70$ \\
Monocytes \% & 7 & $30-50$ \\
Neutrophils \% & 0 & $<2$ \\
Protein mg/dL & 63 & $15-40$ \\
Prealbumin \% & 1.7 & $3.0-7.0$ \\
Albumin \% & 70.8 & $45-70$ \\
a-1 Globulin \% & 2.5 & $3.0-7.0$ \\
a-2 Globulin \% & 5.8 & $5.0-11.0$ \\
$\beta$ Globulin \% & 10.4 & $7.0-13.0$ \\
$\delta$ Globulin \% & 1.7 & $4.0-10.0$ \\
Y Globulin \% & 10.0 & $5.0-14.0$ \\
Glucose mg/dL & 60 & $2 / 3$ glycemia \\
Adenosine deaminase U/L & 1.23 & $<4.0$ \\
Lactate mg/dL & 17.6 & $10-20$ \\
\hline
\end{tabular}

resonance imaging (MRI) was not performed initially due to clinical instability and because transport to another institution was considered life threatening.

Based on the clinical prodrome (weight loss, vomiting, headache with unknown origin), neurological presentation (transverse myelitis, quickly progressing to brainstem dysfunction), compressive cord lesion dismessed by tomographic study, CSF inflammatory abnormalities, and negative workup to more common infectious agents, the diagnosis of neuromyelitis optica (NMO) was highly considered. Pulse therapy with methylprednisolone (1 $\mathrm{g} /$ day for 5 days), in addition to cyclophosphamide (1 $\mathrm{g})$, was started as soon as her neurological status became worse. After 1 week of pulse therapy, her neurological impairment remained unchanged, except for muscle strength grade 3 at wrist extension in both hands. Therefore, intravenous immune globulin $(400 \mathrm{mg} / \mathrm{kg} /$ day for 5 days) was also prescribed. Prednisone $40 \mathrm{mg} /$ day was continued until the next pulse. From that time, her neurological deficits started to gradually improve. She received one more pulse before the hospital discharge. She was discharged without tracheostomy with normal ventilatory parameters, and independent for eating after 40 days of hospitalization. She was unable to walk, but was able to remain seated without aid. The muscle strength was grade 4 with distal predominance in the upper limbs, and was grade 3 proximal and grade 2 distal in the lower limbs. The deep tendon reflexes persisted as brisk in the lower limbs, and hypoactive in the upper limbs, but a brisk finger flexor response was obtained when bicipital reflex was searched in the left side. She also complained of visual blurring at the left eye with normal acuity, although a slightly pale optic disk was detected, and the vertical nystagmus was persistent. The sensory deficit remained at T2 level; however, there was an improvement of the vibratory perception at the knees. She regained the voiding control.

Despite an MRI having been done 20 days after immunosuppressive treatment, areas of signal alteration in the brain stem, optic nerve and tract, left thalamus and basal ganglia with demyelinating features were found at brain imaging study (Figure 1 and 2)

Diffuse signal alteration throughout the cervical and thoracic segment, characterized by elongated hyperintense areas on T2-weighted and FLAIR images, was observed. These areas were predominantly located at the periphery of the cervical 


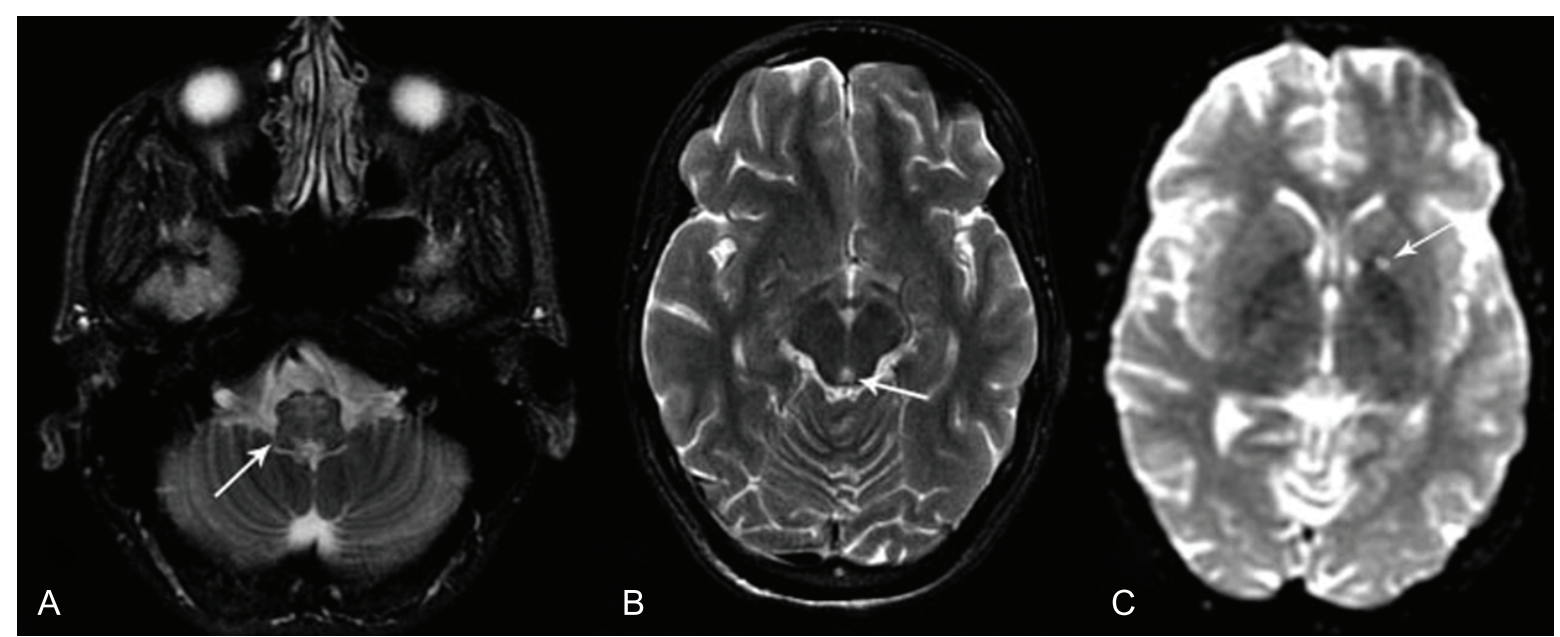

Figure 1 - Axial MRI images of the Brain weighted in T2 showing slight hyperintense areas in the brainstem (pons) (A), periaqueductal (B), and basal ganglia (C) with demyelinating features.

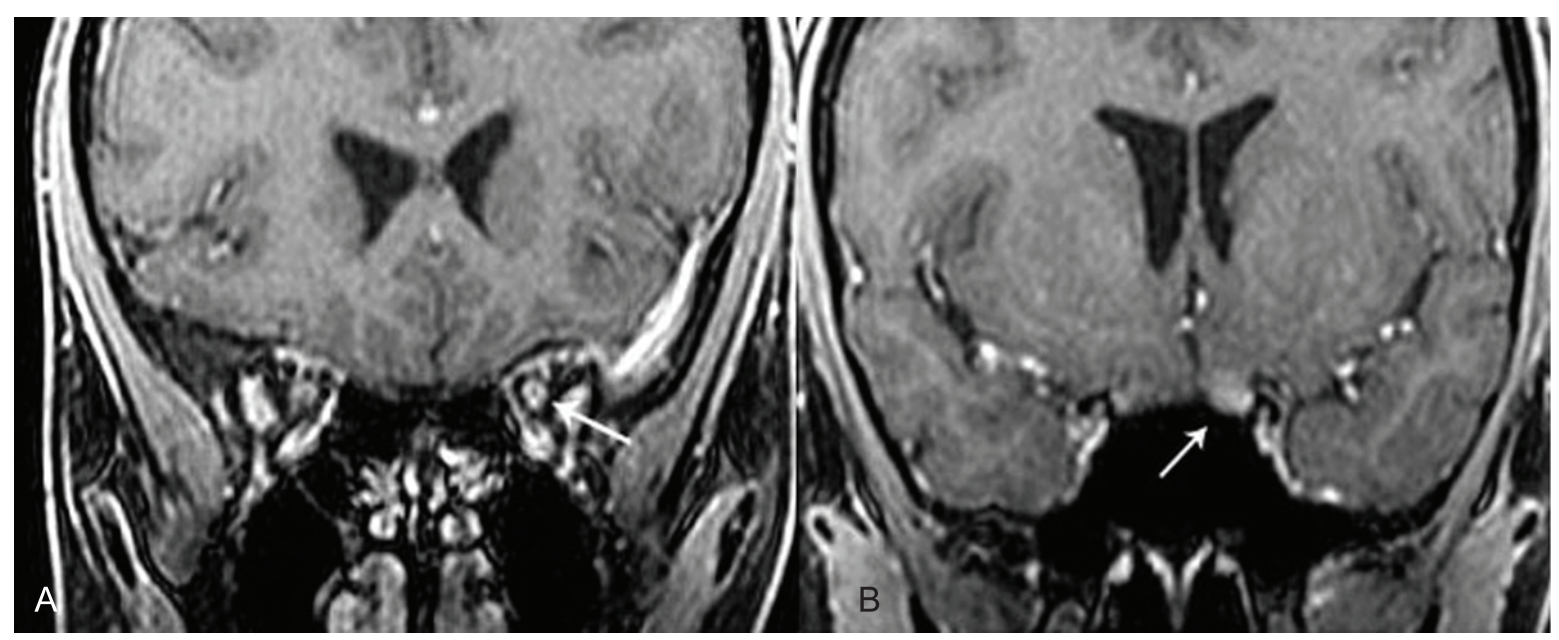

Figure 2 - Coronal MRI images of the Brain weighted in T1 gadolinium injection, showing thickness and contrast enhancement in left optic nerve $(\mathbf{A})$ and tract $(\mathbf{B})$.

level, and centrally located at mid-thoracic level with small areas of vanished gadolinium enhancement. These alterations were continuous and confluent with slight expanding effect (Figure 3).

Tested in a frozen $\left(-20^{\circ} \mathrm{C}\right)$ stored sample, serum IgG-NMO was negative.

\section{DISCUSSION}

Devic's disease or NMO is an idiopathic immune-mediated inflammatory demyelinating disease of the central nervous system (CNS) that selectively affects the optic nerve and spinal cord..$^{1,2}$ Partial or complete, unilateral or bilateral, visual loss represents optic nerve impairment, while para- or tetraplegia or paresis, sensory loss, and sphincter dysfunction exemplify spinal cord involvement.
Historically, the first three cases were reported by Portal in 1804, Pescetto in 1844, and Clarke in $1865 .{ }^{3}$ The first association between myelitis and optic disorder was mentioned by Allbutt in 1870. In 1882, Dreschfeld first suggested that the combination of myelitis and optic neuritis was a clinical syndrome. Devic defined the clinical entity "neuromyélite optique" in 1894, and since then this condition has been called Devic's disease..$^{1,4}$ Several cases and series reports have been published and various diagnostic criteria have been proposed since then. Initially considered as a subtype or clinical variant of multiple sclerosis for many decades, NMO had its own clinical identity, which was defined in 2004 after the discovery of the specific autoantibody (IgG-NMO) whose antigen aquaporin-4 (AQP4) was characterized 1 year later. ${ }^{5,6}$

After the broad clinical NMO definition proposed by Gault and Devic, several diagnostic 

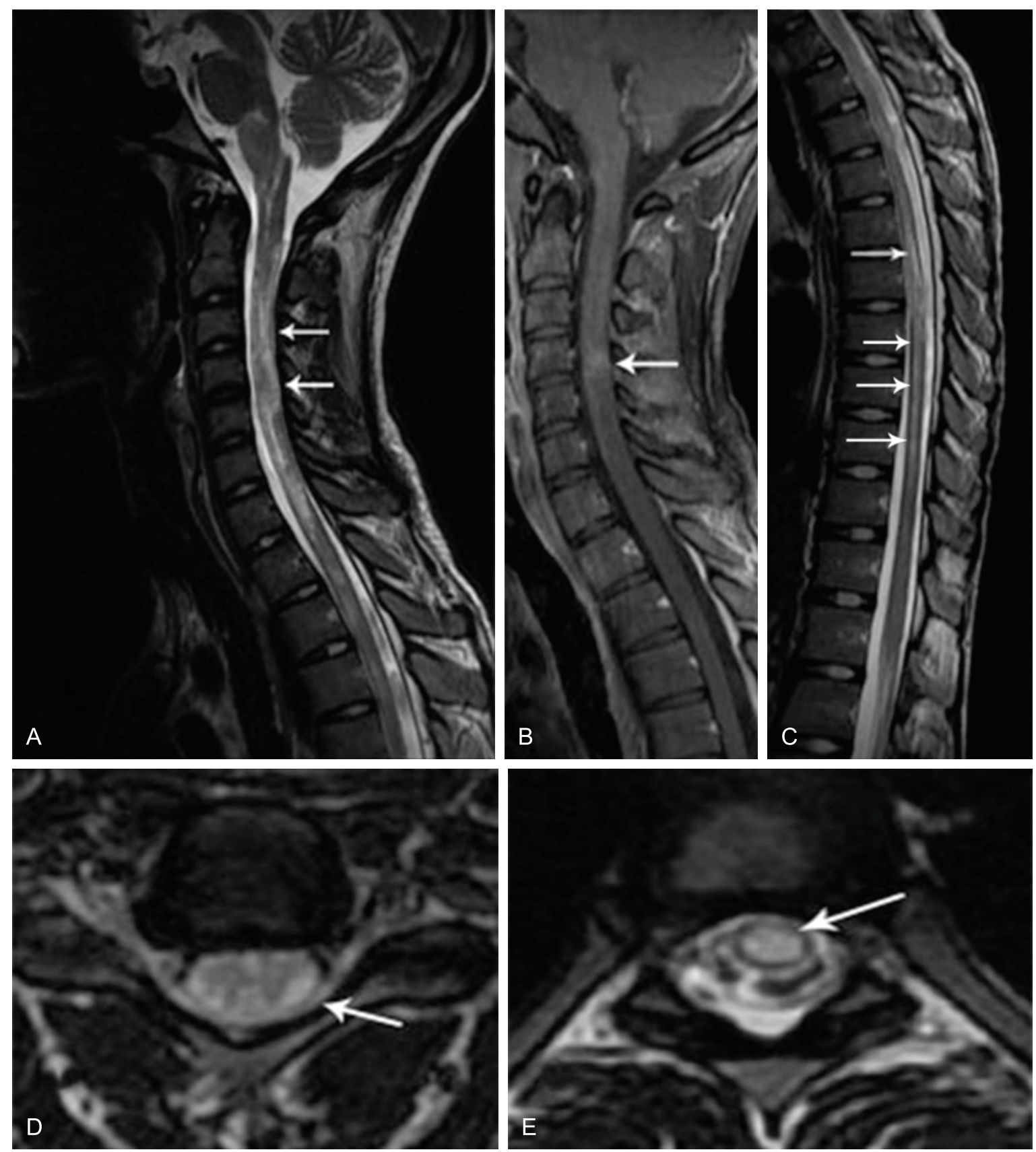

Figure 3 - Sagittal MRI images, (A) of the cervical spine weighted in T2 showing peripheral lesions (arrows), while those of thoracic spine are centrally distributed in (C) (arrows). (B) - sagittal T1 MRI image of the cervical spine after gadolinium injection showing slight enhancement of lesions (arrow). Axial T2 MRI images of de cervical (D) and thoracic (E) spines show hyperintense intramedullary lesions (arrows).

criteria appeared in the literature and some of them are presented in Table 2..$^{711}$ They could roughly be divided into three periods: the first period may be coined as the pre-MRI era in which the diagnosis was only based on clinical findings of spinal cord and/or optic nerve lesion at the same time that other diseases that shared similar neurological symptoms and signs were ruled out. The second period is characterized by the inclusion of MRI abnormalities, and the third period was defined by serum IgGNMO status. Nowadays there is a growing trend to expand the NMO clinical spectrum. ${ }^{12}$
Commonly, the initial presentation of NMO can be visual loss (in $45 \%$ of patients) or myelopathy $(38 \%)$ that usually appear 3 months apart in most cases. The simultaneous involvement of the spinal cord and optic nerve, as was observed in this case report, can occur in $17 \% .^{4,10} \mathrm{~A}$ prodrome of fever, myalgia, sore throat or headache is present in around one-third of cases. In pediatrics, NMO is preceded by infection in $72 \%$ of patients. After the inaugural neurological event, the clinical course may be either monophasic, with no further events, or relapsing with additional attacks of myelitis, optic neuritis or both. ${ }^{1,4}$ Relapsing NMO is twice as frequent than the 
Table 2 - Diagnostic criteria of neuromyelitis optica

\begin{tabular}{|c|c|c|}
\hline Year & Author(s) & Criteria \\
\hline 1894 & Gaut and Devic ${ }^{1,3}$ & $\begin{array}{l}\text { Retrobulbar neuritis or papilitis + acute myelitis } \\
\text { With/without other symptoms or signs not restricted to the spinal cord or } \\
\text { optic nerve }\end{array}$ \\
\hline 1981 & Shibasaki et al. ${ }^{6}$ & $\begin{array}{l}\text { Acute bilateral visual impairment and transverse myelitis occurring succes- } \\
\text { sively }<4 \text { weeks following a monophasic course }\end{array}$ \\
\hline 1993 & Mandler et al. ${ }^{7}$ & $\begin{array}{l}\text { Clinical } \\
\text { 1. Acute lesion of spinal cord and nerve optic, coincidental or separated } \\
\text { by months or years } \\
\text { 2. Without brainstem, cerebellar or cortical features } \\
\text { Imaging } \\
\text { 1. Enlargement and cavitation on spinal cord MRI } \\
\text { 2. Normal-appearing brain MRI } \\
\text { CFS } \\
\text { 1. Decreased serum/CFS albumin ratio } \\
\text { 2. Normal IgG synthesis } \\
\text { 3. Usually absence of oligoclonal bands } \\
\text { Pathology } \\
\text { 1. Spinal cord necrosis and cavitation, thickened vessel walls, absence of } \\
\text { inflammatory infliltrates } \\
\text { 2. Demyelination of optic nerve with or without cavitation } \\
\text { 3. No demyelinating lesions in brain, brainstem, or cerebellum }\end{array}$ \\
\hline 1996 & O'Riordan et al. ${ }^{8}$ & $\begin{array}{l}\text { 1. Complete transverse myelitis evolving over 1-14 days, with sensory level } \\
\text { and in the absence of cord compression } \\
\text { 2. Acute unilateral or bilateral optic neuropathy } \\
\text { 3. No clinical involvement beyond the spinal cord or optic nerves } \\
\text { 4. The disease can be monophasic or multiphasic }\end{array}$ \\
\hline 1999 & Wingerchuk et al. ${ }^{9}$ & $\begin{array}{l}\text { All absolute criteria + one major supportive criterion or two minor supportive } \\
\text { criteria } \\
\text { Absolute criteria } \\
\text { 1. Optic neuritis } \\
\text { 2. Acute myelitis } \\
\text { 3. No evidence of clinical disease outside of the optic nerve or spinal cord } \\
\text { Major supportive criteria } \\
\text { 1. Negative brain MRI at onset } \\
\text { 2. Spinal cord MRI lesion extending over }>3 \text { vertebral segments } \\
\text { 3. CFS pleocytosis of }>50 \mathrm{WBC} / \mathrm{mm}^{3} \text { or }>5 \text { neutrophils } / \mathrm{mm}^{3} \\
\text { Minor supportive criteria } \\
\text { 1. Bilateral optic neuritis } \\
\text { 2. Severe optic neuritis with fixed visual acuity worse than } 20 / 200 \text { in at } \\
\text { least one eye } \\
\text { 3. Severe, fixed, attack-related weakness (MRC grade }<2 \text { ) in one or more } \\
\text { limbs }\end{array}$ \\
\hline 2006 & Wingerchuk et al. ${ }^{10}$ & $\begin{array}{l}\text { Revised criteria for definite NMO } \\
\text { Optic neuritis } \\
\text { Acute myelitis } \\
\text { At least two of three supportive criteria } \\
\text { 1. Contiguous spinal cord lesion extending over }>3 \text { vertebral segments } \\
\text { 2. Bran MRI not meeting diagnostic criteria for multiple sclerosis } \\
\text { 3. NMO-seropositive status }\end{array}$ \\
\hline
\end{tabular}

monophasic type and commonly associated with the female gender, older age onset, less severe motor impairment in the first myelitis attack, and the presence of systemic autoimmunity. ${ }^{1,4,10}$ The neurological impairment is usually more severe in monophasic NMO. The severity of disease onset ranges from fulminant and fatal (around one-third) to recovery with varying degrees of disability. In pediatrics generally, the outcome is favorable with complete neurological recovery. ${ }^{4}$ 
Table 3 - More common differential diagnosis in NMO syndrome

\begin{tabular}{|c|c|}
\hline Systemic immune-mediated inflammatory diseases & $\begin{array}{l}\text { Systemic lupus erytemathosus } \\
\text { Sjögren syndrome } \\
\text { Mixed connective tissue disease } \\
\text { Antiphospholipid antibody syndrome } \\
\text { Sarcoidosis } \\
\text { Paraneoplastic syndrome }\end{array}$ \\
\hline \multicolumn{2}{|l|}{ Infections } \\
\hline Viral & $\begin{array}{l}\text { Cytomegalovirus } \\
\text { Varicella-zoster virus } \\
\text { Epstein-Barr virus } \\
\text { Human immunodeficiency virus }\end{array}$ \\
\hline Bacterial & $\begin{array}{l}\text { Syphilis } \\
\text { Tuberculosis } \\
\text { Borreliosis }\end{array}$ \\
\hline Parasites & $\begin{array}{l}\text { Schistosoma mansonii } \\
\text { Toxocara spp }\end{array}$ \\
\hline Toxicity & $\begin{array}{l}\text { Methanol } \\
\text { Ethylene glycol } \\
\text { Ethambutol } \\
\text { Clioquinol } \\
\text { Chemotherapeutic agents } \\
\text { Radiation }\end{array}$ \\
\hline Nutritional deficiency & Vitamin B12 \\
\hline Idiopathic central nervous system demyelinating diseases & $\begin{array}{l}\text { Multiple sclerosis } \\
\text { Neuromyelitis optica } \\
\text { Acute disseminated encephalomyelitis } \\
\text { Idiopathic optic neuritis }\end{array}$ \\
\hline Neoplasia & Lymphoma \\
\hline
\end{tabular}

In the case of this report, the earliest symptoms were vomiting, weightloss, and headache. Currently, it is well known that approximately $15 \%$ of NMO patients have symptoms and signs indicating disease outside the optic nerve and spinal cord, which can antedate or occur during the course of the disease.1,10,12 Some of these cases could be justified by high expression of AQP 4 and consequent susceptibility to immune attack by the antibody anti-AQP4. For instance, intractable hiccups, nausea, and vomiting are the most common brain symptoms in NMO due to involvement of the area postrema. In addition, hypothalamic lesions could explain anorexia and weigh loss, hyperphagia and obesity, hypothermia, fever, syndrome of inappropriate secretion of antidiuretic hormone and other endocrine dysfunction, diffuse anhydrose, bradycardia, hypotension, and recurring episodes of coma. Confusion, decreased consciousness, coma, ocular movement disturbances, retrochiasmal visual field defects, cortical blindness, seizures, and aphasia could be present as encephalopathic manifestations.
NMO has been associated with other autoimmune diseases, which are a part of large differential diagnosis presented in Table 3 . Antinuclear antibodies (ANA), anti-SSA, antiSSB, anti-cardiolipin, perinuclear antineutrophil cytoplasmatic (ANCA), anti-thyroid peroxidase are some examples of circulating autoantibodies that can occur without their associated systemic clinical condition. ${ }^{1}$

Regardless of differences in the data collection and diagnostic criteria, several authors have reported that $\mathrm{NMO}$ is more prevalent in areas with Black, Asian, and Indian populations. ${ }^{1,13}$ For example, in North American and European countries, NMO constitutes less than $1 \%$ of $\mathrm{CNS}$ demyelinating diseases while it accounts for $98 \%$ and $17.3 \%$ in Nigerian and French AfricanCaribbean nationalities, respectively. ${ }^{4,14,15}$ Few Brazilian studies disclosed $11 \%$ of Devic's disease diagnosed among African descendants. ${ }^{16,17}$ Women are overrepresented in all NMO series; for instance, 9:1 in China, 5:1 in Brazil, and 9:1 in Martinique. In the USA, rates of $1: 1$ in monophasic NMO and $5: 1$ in recurrent NMO are shown. ${ }^{1}$ The median age of 
symptoms onset ranges from 40 years in relapsing NMO and 29 years in the monophasic type. The median age in pediatrics was 4.4 years. ${ }^{1,4,18}$

Since the phenotype of NMO can be shared with several diseases in which optic neuritis and myelitis are present isolated or simultaneously, the differential diagnoses are very broad and should be carefully explored (Table 3 ).

An ally to cardinal neurological symptoms and signs, MRI is one of the most important auxiliary exams for NMO diagnosis. As observed in the case reported here, the spinal cord study shows longitudinally extensive areas of increased signal intensity on T2-weighted and FLAIR images (demyelinating features) extending through several vertebral segments, with varying degrees of gadolinium enhancement on T1-weighted images, and, in the acute phase, a marked swelling of the cord could simulate a tumorigenic lesion. ${ }^{12,19} \mathrm{~A}$ cavity is seen in cases with severe disease, and cord atrophy appears in late stages. Brain MRI may be normal or show nonspecific changes; when white matter abnormalities are present, they are considered "not typical for multiple sclerosis" or, characteristically, are found in areas with high expression of AQP4 (hypothalamus, areas surrounding the third and fourth ventricles). ${ }^{20}$ The optic nerve can show the same demyelinating features.

Another diagnostic auxiliary exam is CFS analysis. Commonly, cell counts are less than 50 cells $/ \mathrm{mm}^{3}$ in which neutrophils and eosinophils may be present. ${ }^{9}$ Generally, protein content is increased, IgG index is normal, and oligoclonal bands are usually absent. ${ }^{21}$

Serum identification of IgG-NMO has an important role in diagnostic workup. Nowadays there are several laboratory assays based on indirect immunofluorescence. The first and more widespread laboratory technique uses mouse brain tissues as substrate and shows a sensitivity ranging from $55 \%$ to $73 \%$ and specificity from $90 \%$ to $100 \%$. Albeit not commercially available and using human AQP4-transfected cells as substrate, this test has $73-91 \%$ of sensitivity and $100 \%$ of specificity for NMO..$^{1,12}$

Considering the immunopathogenesis of $\mathrm{NMO}$, since very early the demyelination of optic nerve and spinal cord were observed along with polymorphonuclear infiltrates. In 1949, it was suggested that pathological lesion occurred in stages with perivascular inflammation being the earliest. ${ }^{22}$ As recently demonstrated in an autopsy series, immunoglobulin deposition, activated complement, eosinophils, and myelin protein reactive macrophages were found in the perivascular space of spinal cord blood vessels suggesting that this space was the target for humoral autoimmune attack. ${ }^{23}$ This research culminated in the identification of IgG-NMO that binds to AQP4 in the abluminal face of cerebral microvessels which correspond to astrocytic foot processes. ${ }^{5,6}$

Aquaporins encompass a family of water channels, which control the water transport in several organs. AQP4 is the most abundant aquaporin in the mammalian brain (astrocytes and ependymal cells) and its loss may result both in severe damage of myelin and axons in vulnerable areas in which it is overexpressed (spinal cord, optic nerves, hypothalamus, and periventricular and periaqueductal structures). ${ }^{24,25}$ Although useful for diagnostic purposes, IgG-NMO titer has no correlations with disease duration, the number of relapses, or the effects of immunotherapies. ${ }^{1}$ In addition, there is no definite evidence that anti-AQP4 antibody causes NMO because its administration to experimental models does not reproduce the disease and AQP4-knockout mice do not express the NMO phenotype. Also, other questions remain unanswered, such as the predominance of spinal cord and optic nerve lesions, while AQP-4 is ubiquitously expressed throughout - not only in CNS, but also in kidneys, lungs, inner ear, and intestine. Lastly, one could ask, what trigger event opens the blood-brain barrier?

NMO treatment starts with high-dose intravenous methylprednisolone (1 g/day for 5 consecutive days). ${ }^{1}$ In cases of corticotherapy resistance, plasma exchange therapy is helpful but does not prevent further relapses. ${ }^{10,26}$ Lymphocytapheresiscould beusedinbilateralblinded and tetraplegic patients who were unresponsive to high-dose intravenous corticosteroid and plasma exchange or intravenous immunoglobulin treatment. ${ }^{27}$ This therapeutic protocol is also applied to recurrent attacks. Early prophylactic treatment is recommended, mainly in IgG-NMO-positive patients, to avoid future relapses. ${ }^{1}$ From anecdotal published experiences in NMO treatment, each service designed its own drug protocol, generally based on immunosuppressive drugs (azathioprine, cyclophosphamide, methotrexate, mitoxantrone, mycophenolate mofetil). ${ }^{28-31}$ More recently, rituximab 
(chimeric murine/human monoclonal anti-CD20) has been used showing a decrease in the relapse rate and improvement in neurological disability. ${ }^{32}$

Using neatly clinical criteria as stated by O'Riordan et al. ${ }^{9}$ in 1996, NMO was suspected in our patient. When MRI had been done, the 1999 Wingerchuck et al. ${ }^{10}$ criteria were obeyed. The longitudinally and extensive spinal cord and brain lesions at MRI studies were all concordant with literature data. Taking into account the low sensitivity of IgG-NMO commercially available, a negative result did not exclude this diagnosis. Taking in account the severity of clinical presentation, and bearing in mind the massive inflammatory infiltration pathological process involved in this entity, which can lead to tissue destruction (cavitation), an early immunosuppressant therapy was added to corticosteroid and thereafter complemented by intravenous immunoglobulin.

\section{CONCLUSION}

In a secondary health setting, NMO diagnosis is a challenging one because MRI and IgG-NMO reactions are not easily available. These important subsidiary exams have to be done at tertiary or private hospitals and they take time. In severe neurological involvement, this delay can be life threatening. In addition, therapeutic options as plasma exchange and intravenous immunoglobulin are not easily available. After a fast exclusion of infectious diseases, we assume that prompt immune therapeutic intervention is fundamental for achieving more favorable outcomes.

\section{REFERENCES}

1. Lana-Peixoto MA. Devic's neuromyelitis optica: a critical review. Arq Neuropsiquiatr. 2008;56:120-38. http://dx.doi. org/10.1590/S0004-282X2008000100034

2. Bomprezzi R, Postevka E, Campagnolo D, Vollmer $T L$. A review of cases of neuromyelitis optica. Neurologist. 2011;17:98-104. PMid:21364364. http://dx.doi. org/10.1097/NRL.0b013e31820a9d35

3. Jarius $\mathrm{S}$, Wildemann B. The case of the Marquis de Causan (1804): an early account of visual loss associated with spinal cord. J Neurol. 2012;259:1354-7. PMid:22237820. http:// dx.doi.org/10.1007/s00415-011-6355-8
4. Cree BAC, Goodin DS, Hauser SL. Neuromyelitis optica. Neurology. 2002;22:105-22.

5. Lennon VA, Wingerchuck DM, Kryser TJ, et al. A serum autoantibody marker of neuromyelitis optica: distinction from multiple sclerosis. Lancet. 2004;364:2106-12. http:// dx.doi.org/10.1016/S0140-6736(04)17551-X

6. Lennon VA, Kryser TJ, Pittock SJ, Verkerman AS, Hinson SR. IgG marker of optic-spinal multiple sclerosis binds to the aquaporin-4 water channel. J Exp Med. 2005;202:473-7. PMid:16087714 PMCid:2212860. http://dx.doi.org/10.1084/ jem.20050304

7. Shibasaki H, McDonald WI, Kuroiwa Y. Racial modification of clinical picture of multiple sclerosis comparison between British and Japanese patients. J Neurol Sci. 1981;49:253-71. http://dx.doi.org/10.1016/0022-510X(81)90083-6

8. Mandler RN, Davis LE, Jeffery DR, Kornfeld M. Devic's neuromyeloitis optica: a clinical pahological study of 8 patients. Ann Neurol. 1993:34:162-8. PMid:8338340. http:// dx.doi.org/10.1002/ana.410340211

9. O'Riordan JI, Gallagher HL, Thompson AJ, et al. Clinical, CSF, and MRI findings in Devic's neuromyelitis optica. $J$ Neurol Neurosurg Psychiatry. 1996;60:382-7. PMid:8774400 PMCid:1073888. http://dx.doi.org/10.1136/jnnp.60.4.382

10. Wingerchuk DM, Hogancamp WF, O'Brien PC, Weinshenker BG. The clinical course of neuromyelitis optica (Devic's syndrome). Neurology. 1999;53:1107-14. PMid:10496275. http://dx.doi.org/10.1212/WNL.53.5.1107

11. Wingerchuk DM, Lennon VA, Pittock SJ, Lucchinetti CF, Weinshenker BG. Revised diagnostic criteria for neuromyelitis optica. Neurology. 2006;66:1485-9. PMid:16717206. http:// dx.doi.org/10.1212/01.wnl.0000216139.44259.74

12. Lana-Peixoto MA, Callegaro D. The expanded spectrum of neuromyelitis optica - evidences for a new definition. Arq Neuropsiquiatr. 2012;70:807-13. http://dx.doi.org/10.1590/ S0004-282X2012001000010

13. Nagaishi A, Takagi M, Umemura A, et al. Clinical features of neuromyelitis optica in a large Japanese cohort: comparison between phenotypes. J Neurol Neurosurg Psychiatry. 2011;82:1360-4. PMid:21665917. http://dx.doi. org/10.1136/jnnp-2011-300403

14. Osuntokun BO. The pattern for neurological illness in tropical Africa: experience of Ibadan, Nigeria. J Neurol Sci. 1971;12:417-20. http://dx.doi.org/10.1016/0022$510 \times(71) 90110-9$

15. Cabre $P$, Heinzlef $\mathrm{O}$, Merle $\mathrm{H}$, et al. MS and neuromyelitis optica in Martinique (French West Indies). Neurology. 2001;56:507-14. PMid:11222796. http://dx.doi. org/10.1212/WNL.56.4.507

16. Lana-Peixono MA, Lana-Peixoto MI. Is multiple sclerosis in Brazil and Asia alike? Arq Neuropsiquiatr. 1992;50:419-25. http://dx.doi.org/10.1590/S0004-282X1992000400002 
17. Papais-Alvarenga $\mathrm{R}$, Miranda-Santos CM, PuccioniSohler M, et al. Optic neuromyelitis syndrome in Brazilian patients. J Neurol Neurosurg Psychiatry. 2002;73:429-35. PMid:12235313 PMCid:1738088. http://dx.doi.org/10.1136/ jnnp.73.4.429

18. Banwell B, Tenembaum S, Lennon VA, et al. Neuromyelitis optica-lgG in childhood inflammatory demyelinating CNS disorders. Neurology. 2008;70:344-52. PMid:18094334. http://dx.doi.org/10.1212/01.wnl.0000284600.80782.d5

19. Filippi M, Rocca MA, Moiola L, et al. MRI and magnetization transfer imaging changes in the brain and cervical cord of patients with Devic's neuromyelitis optica. Neurology. 1999;53:1705-10. PMid:10563616. http://dx.doi. org/10.1212/WNL.53.8.1705

20. Pittock SJ, Weinshenker BG, Lucchinetti CF, Wingerchuk DM, Corboy JR, Lennon VA. Neuromyelitis optica brain lesions localized at sites of high aquaporin 4 expression. Arch Neurol. 2006;63:964-8. PMid:16831965. http://dx.doi. org/10.1001/archneur.63.7.964

21. Nakashima I, Fujihara K, Fujinori J, Narikawa K, Misu T, Itoyama Y. Absence of lgG1 response in the cerebrospinal fluid of relapsing neuromyelitis optica. Neurology. 2004;62:144-6. PMid:14718720. http://dx.doi.org/10.1212/WNL.62.1.144

22. Stansbury FC. Neuromyelitis optica (Devic's disease): presentation of five cases with pathological study and review of the literature. Arch Ophtalmol. 1949;42:465-501. http://dx.doi.org/10.1001/archopht.1949.00900050473014

23. Luccinetti CF, Mandler RN, McGovern D, et al. A role for humoral mechanisms in the pathogenesis of Devic's neuromyelitis optica. Brain. 2002;125:1450-61. http://dx.doi. org/10.1093/brain/awf151

24. Griesdale DE, Honey CR. Aquaporins and brain edema. Surg Neurol. 2004;61:34-9. PMid:15120208. http://dx.doi. org/10.1016/j.surneu.2003.10.047
25. Benarroch. EE. Aquaporin-4, homeostasis, and neurologic diseases. Neurology. 2007;69:2266-8. PMid:18071147. http:// dx.doi.org/10.1212/01.wnl.0000286385.59836.e2

26. Weinshenker BG, O'Brien PC, Petterson TM, et al. A randomized trial of plasma exchange in acute inflammatory central nervous system demyelinating diseases. Ann Neurol. 1999;46:878-86. http://dx.doi.org/10.1002/15318249(199912)46:6<878::AID-ANA10>3.0.CO;2-Q

27. Nazaki I, Hamaguchi T, Komai K, Yamada M. Fulminant Devic's disease successfully treated by lymphocytapheresis. J Neurol Neurosurg Psychiatry. 2006;77:1094-102. PMid:16614009 PMCid:2077763. http://dx.doi.org/10.1136/ jnnp.2005.086306

28. Mandler RN, Ahmed W, Dencoff JE. Devic's neuromyelitis optica: a prospective study of seven patients treated with prednisone and azathioprine. Neurology. 1998;51:1219-20. PMid:9781568. http://dx.doi.org/10.1212/WNL.51.4.1219

29. Minagar A, Sheremata WA. Treatment of Devic's disease with methotrexate and prednisone. Int J MS Care. 2000;2:39-43. http://dx.doi.org/10.7224/1537-2073-2.4.43

30. Weinstock-Guttman B, Ramanathan M, Lincoff N, et al. Study of mitoxantrone for the treatment of recurrent neuromyelitis optica (Devic's disease). Arch Neurol. 2006;63:957-63. PMid:16831964. http://dx.doi.org/10.1001/archneur.63.7.957

31. Falcini F, Trapani S, Ricci L, Resti M, Simonini G, Martino M. Sustained improvement of a girl affected with Devic's disease over 2 years of mycophenolate mofetil treatment. Rheumatology. 2006;45:913-5. PMid:16638802. http://dx.doi. org/10.1093/rheumatology/kei263

32. Cree BAC, Lamb S, Morgan K, Chen A, Waubant E, Genain C. An open label study of the effects of rituximab in neuromyelitis optica. Neurology. 2005;64:1270-2. PMid:15824362. http:// dx.doi.org/10.1212/01.WNL.0000159399.81861.D5

\section{Conflict of interest: None}

Submitted on: $26^{\text {th }}$ December 2012

Accept on: $15^{\text {th }}$ February 2013

Correspondence: Instituto de Infectologia Emílio Ribas - Divisão Científica

Av. Dr. Arnaldo, 165 - São Paulo/SP - Brazil

CEP: 01246-900 - Phone: +55 (11) 98231.7986

E-mail: annaminczuk@yahoo.com.br 
